\title{
Low Grade Endometrioid Stromal Sarcoma of the Cervix
}

National Cancer Institute

\section{Source}

National Cancer Institute. Low Grade Endometrioid Stromal Sarcoma of the Cervix. NCI

Thesaurus. Code C40222.

A very rare sarcoma that arises from the cervix and is characterized by the presence of cells that resemble endometrial stromal cells. 